\title{
Innovative Magnetron Sputtering For the Synthesis of Catalytic and Nanostructured Materials and Its Possible Using In Biomedicine and In the Fight against COVID-19
}

\author{
Zaur Berishvili, Marina Kipiani, Irakli Kordzakhia, Guram Dekanozishvili
}

\begin{abstract}
The demand for catalytic and nanostructured materials is growing, which contributes to the development of new methods and technologies for their synthesis. Magnetron sputtering in vacuum is one of the popular methods for this task, characterized by simplicity, flexibility of use, and high productivity; However, it has a number of disadvantages, the main of which is the inhomogeneity of the intensity of the ion bombardment of the target, which causes the formation of a narrow zone of erosion and rapid wear of the target material, respectively, inhomogeneity in the thickness and composition of the materials obtained. The innovative design and technology of planar magnetron sputtering with a rotating magnetic block presented in the article completely eliminate these and other disadvantages. Among the innovations: an original mathematical method for calculating the configuration of a closed magnetic field, which made it possible to implement a new physical mechanism of magnetron sputtering of the target surface. The improved stability of technological processes and the possibility of controlled operation of them make it possible to obtain high quality two-dimensional materials. In addition, the article presents a method developed by us for magnetron ion-plasma electrodispersion in vacuum of a bulk target material, based on the creation of a compact reactor for the synthesis of catalytic nanoparticles and three-dimensional nanostructured materials. The content of the method lies in the formation of a flow of charged liquid macrodroplets of the target material and a zone of cascade fission of macrodroplets in the volume of a toroidal magnetron plasma continuously moving above the target surface. The principle of operation of the reactor provides a wide possibility of creating conditions for the formation of monodisperse nanomaterials, homogeneous in chemical composition and with an amorphous structure. Due to the uniqueness of the presented technology, it can be tested for successful use in the context of obtaining such important materials for today, which could be effectively implemented in the fight against the covid 19 pathogen.
\end{abstract}

Index Terms - Magnetron, synthesis, nanoparticles, reactor, agglomeration, plasma, target.

Zaur Berishvili, Senior Researcher of LEPL Institute "Optica", Ass. Professor of Caucasus University, Tbilisi, Georgia

Marina Kipiani, Senior Researcher, Deputy Head of LEPL Institute "Optica", Tbilisi, Georgia

Irakli Khordzakhia, Chief Scientist, Head of the Department of LEPL Institute "Optica", Tbilisi, Georgia

Guram Dekanozishvili, Senior Researcher of E. Andronikashvili Institute of Physics, I. Javakhishvili Tbilisi State University, Tbilisi, Georgia

"This article is dedicated to the memory of those killed as a result of Covid 19 and, in particular, to Anzor Berishvili."

\section{INTRODUCTION}

The growing demand for highly efficient catalytic materials, such as, for example, two-dimensional composite catalytic materials, intermetallic compounds in catalysis, nanocatalysts, etc., has led to the development of new innovative methods and technologies for synthesis. Among the numerous methods for preparing catalytic materials, a prominent place is occupied by the method of magnetron sputtering in vacuum. The method is distinguished by its simplicity, flexibility in use, and high productivity.

Currently, magnetron sputtering is one of the main widespread vacuum methods for obtaining not only catalytic materials $[1,2,3,4]$, but also materials for biomedical purposes $[5,6,7,8,9,10,11]$, for devices in the field of renewable energy, etc. $[12,13,14]$. In recent years, there is a stabile high interest in research in this area (Fig. 1). Source of information Google.

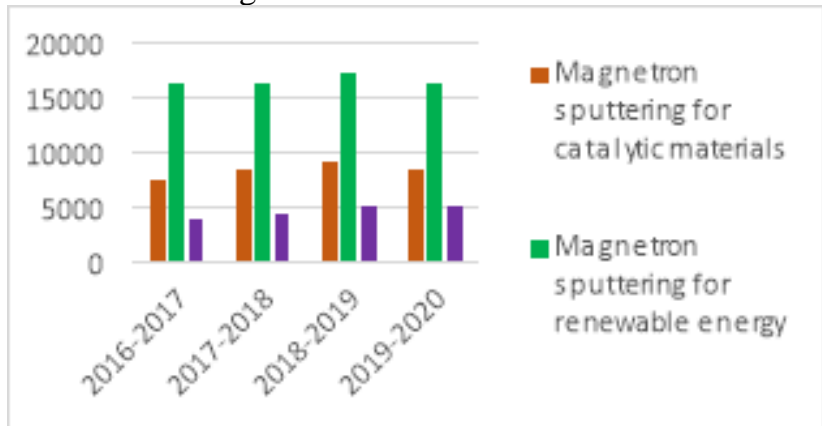

Fig.1 Static data plot

\section{A. Planar magnetron sputtering device}

The main line of development of magnetron sputtering technology in vacuum until now has been associated with the development of a planar magnetron sputtering system in the 70s of the last century. In 1973 J.F. Korbani and in 1974 J.S. Chapin proposed the design of a magnetron sputtering device, the operating principle of which is shown in (Fig. 2)[16,17].

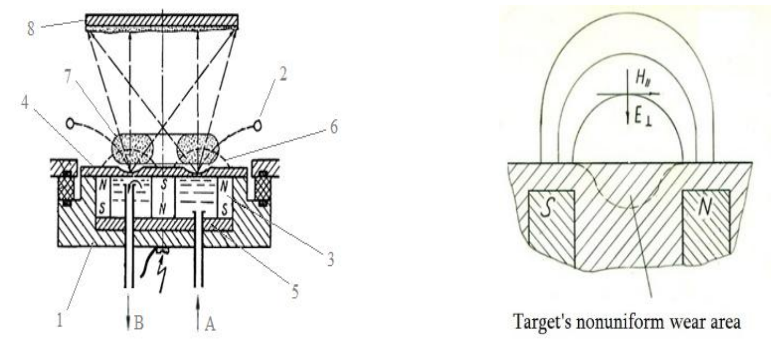

Fig.2. Flat-cathode magnetron spraying apparatus 
1 - cathode assembly, 2 - anode, 3 - permanent magnets, 4 target, 5 - holder of the magnetic system, 6 - configuration of the magnetic field, 7 - magnetron plasma, 8 - substrate, A coolant inlet, B - coolant outlet

However, along with its great popularity, the method has a number of disadvantages: heterogeneity intensity of ion bombardment of the target; the target erosion zone has the form of a deep and narrow ring-shaped recess, which reduces its service life and complicates the technological process; inhomogeneity in thickness and composition of the obtained two-dimensional composite catalytic materials. The utilization factor of the target material does not exceed $30 \%$ of its volume (Fig. 3).

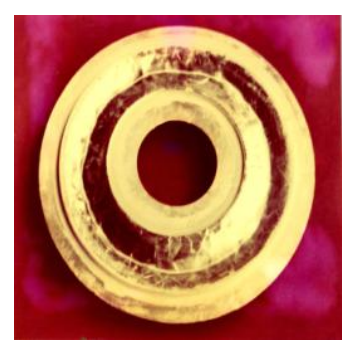

a)

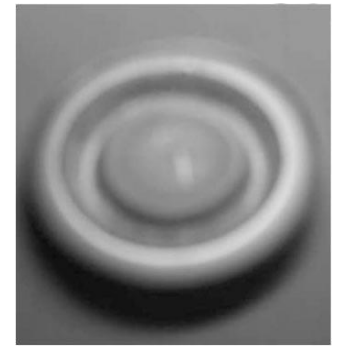

b)
Fig.3 Ineffective use of the target material

a) Z.V.Berishvili et.st [18, 2017];

b) Shyjumon I, Ph.D. Thesis (Greifswald: Greifswald Univ., 2005)

\section{B. Innovative planar magnetron sputtering device}

A real breakthrough in the design of new constructions of magnetron sputtering devices and coating technologies is the emergence of a new generation of magnetron sources created by us - a planar magnetron sputtering device (PMSD) with a rotating magnetic unit [18].

The main advantages of the innovative PMSD are:

A liquid cooling system in which a flow of coolant is used in a cathode assembly to rotate a magnetic unit;

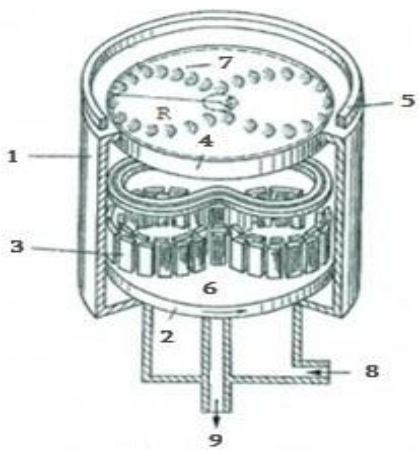

Fig. 4. Construction of PMSD with rotating magnetic block.

1-cathode assembly, 2-magnetic system holder, 3-array of permanent magnets, 4-annular target cathode, 5-anode, 6-magnetic conductor, 7-plasma (area of erosion), 8-coolant inlet, 9 -coolant outlet

Due to the movement of the coolant in the cathode assembly with large-scale turbulence, it acquires an increased ability to absorb heat (approximately 3-4 times), and this provides effective cooling of the sputtered target and the cathode assembly as a whole (Fig. 4) [19].
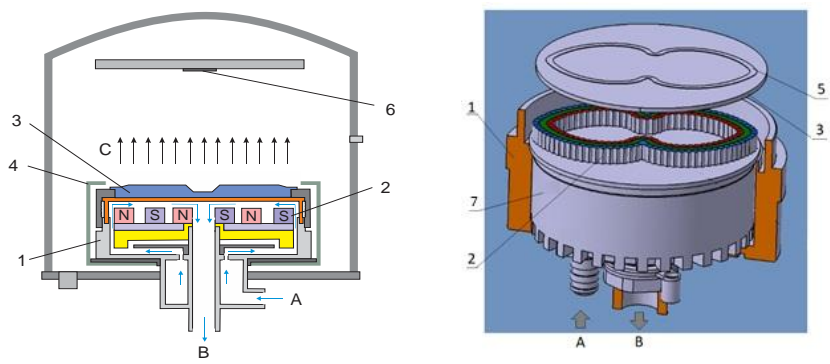

Fig. 5 Construction of PMSD with rotating magnetic block

1 - cathode assembly, 2 - array of permanent magnets, 3 annular target cathode, 4 - anode, 5 - plasma (area of erosion), 6 - substrate, 7 - turbine, A - coolant inlet, B - coolant outlet, C - spray of particles

The use of traditionally used structural elements of the turbine in PMSD for rotation of the magnetic system ensured high reliability during operation of the magnetron (Fig. 5).

To ensure a uniform zone of erosion of the sputtered disk target and stability of the stationary state of the plasma, its region above the target must be closed and have a constant width. Expression for the axial line, which determines the optimal configuration of the plasma region:

$$
\varphi+C=\frac{\sqrt{r^{2}-r_{0}^{2}}}{r_{0}}-\arccos \frac{r_{0}}{r}
$$

where $\varphi$ and $r$ are the coordinates of the current point of the involute in the polar coordinate system with the pole at the center of the circular target; $\mathrm{r}_{-} 0$ is the radius of the non-sprayed area of the target. C is a constant coefficient determined from the condition of the involute cliquishness [20].

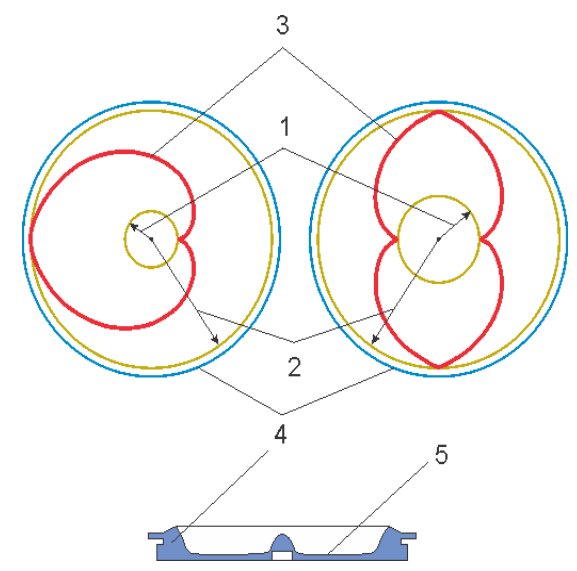

Fig.6 Configuration of a closed magnetic field and amortized target

$1-\mathrm{r}_{0}$ - radius of the non-sputtered target zone, 2 - $\mathrm{R}$ - outer radius of the target sputtering zone, 3 - involute line, 4 amortized target, 5 - flat bottom of the target erosion zone. 
The use of the mathematical method of calculation made it possible to create such a configuration of a closed magnetic field, in which the intensity vector during rotation is parallel to the surface of the target in almost the entire area above the round target; The inhomogeneous intensity of ion bombardment in the stationary mode, with the rotation of the magnetic system, is transformed into a new physical mechanism of magnetron sputtering of the target surface, which has a significant effect on the stability of technological processes and the physical characteristics of the obtained two-dimensional films of catalytic materials.
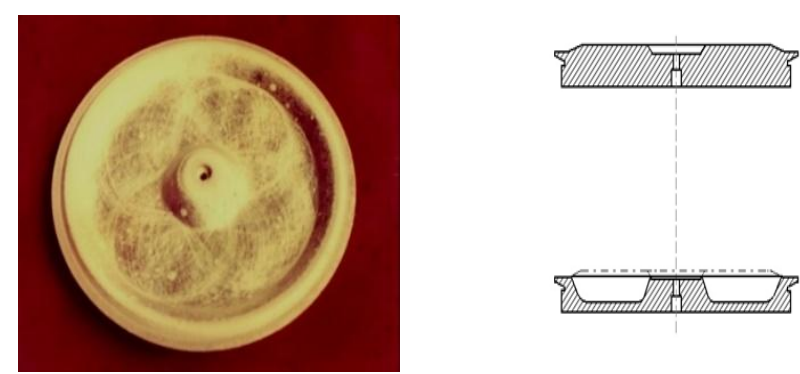

a) b)

Fig.7 A picture of the process of erosion of a disk target

a) Efficient use of the target material, Z.V.Berishvili et.st [18, 2017];

b) Profile of the target before and after sputtering.

A new innovative picture of the process of erosion of a round target has been implemented, which allows during the sputtering process to keep the profile of the bottom of the target erosion zone flat and uniform on $80-90 \%$ of its surface, and further in the volume (Fig. 7) [21,22].

\section{Electrodispersion methods}

The prospect of using nanoparticles is mainly related to two circumstances. First, as the particle size decreases, the number of atoms on the surface increases and their number in the volume decreases. Consequently, catalysts consisting of nanoparticles have a large surface area and are active in homo and heterogeneous reactions. Second, this is the size effect; many characteristics of nanoparticles depend on their structure and size. Consequently, the retention of the amorphous structure and a decrease in the diameter of nanoparticles to several nanometers can enhance the activity and selectivity of nanocatalysts and nanostructured materials.

Laser electrodispersion - is a recently developed method of electrodispersion [23] that provides an conversion of mono- and bimetallic materials into amorphous nanoparticles. The implementation of this method is based on the use of the process of electrodispersion of the material of a metal target under the influence of a high-power plus-periodic laser. Under the action of a laser pulse, a hot plasma of the laser torch is formed near the target surface, the temperature and density of which is determined by the material of metal and the target irradiation conditions. In the plasma of the laser torch, liquid metal droplets injected from the target surface are charged to a critical value, up to the capillary (Relay) instability threshold, upon reaching which the droplets begin to split, generating many smaller (daughter) droplets. The daughter drops are charged above the instability threshold, and as a result, the process of cascade division begins. An abrupt termination of division occurs when the size of daughter droplets reaches several nanometers. It is important that, due to rapid cooling, the resulting solid nanoparticles do not have time to crystallize and remain in an amorphous state. The average size of the obtained monometallic $(\mathrm{Cu}, \mathrm{Ni}, \mathrm{Pt}, \mathrm{Pd}$, etc.) and bimetallic ( $\mathrm{NiPd}, \mathrm{NiAu}$, etc.) nanoparticles is about $2-4 \mathrm{~nm}$, and the relative dispersion is about $10 \%$. Thus, the particles obtained by the method of laser electrodispersion can be considered monodisperse. The combination of monodisperse size distribution and amorphous state of nanoparticles makes them a unique material for use in catalysis [24, 25, 26].

\section{Electrodispersion of liquid droplets in a vacuum -}

Is a method for producing nanoparticles in a vacuum involves dispersing a material by applying an electric field with a voltage at the tip of the apex of $107 \mathrm{~V} / \mathrm{cm}$ to a cathode made of a conductive material with a tip curvature radius of no more than $10 \mu \mathrm{m}$. The resulting liquid droplets are fed into a separate vacuum chamber, where an electric discharge plasma is created in an inert gas at a pressure of 10-2-10-1 Pa. At the same time, the plasma is affected by a magnetic field with a strength of at least $600 \mathrm{G}$, perpendicular to the electric field. This ensures that the droplets reach a charge exceeding the critical value of the Relay instability threshold, leading to cascade fission, nanostructuring of liquid microdroplets, and their rapid solidification [27, 28].

Magnetron electrodispersion is a method of magnetron ion-plasma electrodispersion of liquid-phase drops in vacuum based on the creation of a compact reactor for the synthesis of nanoparticles. The original design of the magnetron reactor and the technology of ion-plasma electrodispersion are described in the patent document [29]. The method developed by us for the formation of catalytic and nanostructured materials during the sputtering of the target material includes the formation of a flow of macrodroplets in the target region and their cascade fission in the region of a toroidal magnetron plasma. The formation and electrodispersion of macrodroplets occurs under the action of intense ion bombardment of the target between the inputs and outputs of the magnetic field lines in a closed-loop configuration. The configuration of this closed magnetic field contour with a target erosion zone width of 2-5 mm provides stimulation in the active zone of "electrical instabilities, such as arcs" [30] or "the spoke's edge" [31,32] and accompanies the formation of a magnetron ion-plasma electrodispersion of liquid-phase drops. At the same time with the atomized atoms and molecules, macrodroplets fly out from the target surface and getting caught the volume of the toroidal magnetron plasma. Sputtered atoms and molecules of the target material freely pass through the toroidal magnetron plasma and are precipitated on the substrate. Macrodroplets of the target material in the volume of a toroidal magnetron plasma undergo additional charging and further, as a result of the development of the process of Relay or capillary instability in the plasma, cascade fission. Daughters of a macrodroplet 
formed in the process of cascade fission are also unstable, and we get a cascade decay of droplets to the size $\left(d_{\min } \approx 8 \cdot 10^{-7} \varepsilon_{0} \alpha^{-3}\right)$. At this size the particles lose charge as a result of the electronic emission [33]. The process self-organization, i.e.of cooling and solidification of nanoparticles occurs outside the plasma region in a vacuum space, when they freely fall along a spiral trajectory between the target surface and the substrate holder (Fig. 9).

This excludes the risk of an increase in the size of nanoparticles as a result of maturation or Oswald agglomeration. As a result of rapid cooling (cooling rate $106 \mathrm{~K} / \mathrm{s}$ ), the resulting nanoparticles keep their spherical shape and amorphous structure. Exactly Similar to the method of laser electrodispersion, the size of nanoparticles is 2-4 $\mathrm{nm}$, and the relative dispersion is about 10\% (Fig.8) [29].

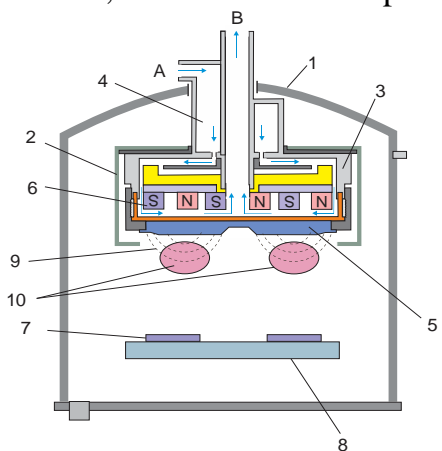

a)

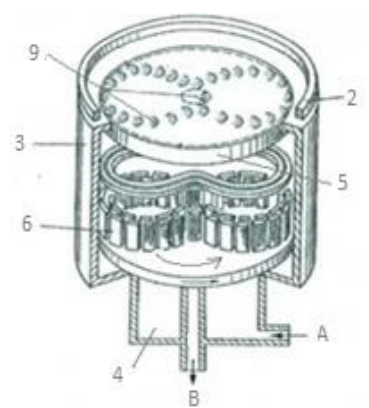

b)
Fig.8. a) Vacuum apparatus for magnetron ion-plasma electrodispersion;

b) Innovative planar magnetron sputtering device with rotating magnetic block

1 - vacuum chamber, 2 - anode, 3 - cathode, 4 - liquid cooling system, 5 - disk target, 6 - matrix of permanent magnets, 7 - substrate, 8 - holder substrate, 9 - rotating magnetic field, 10 - generated magnetron plasma. A - coolant inlet, B - coolant outlet

The method of magnetron ion-plasma electrodispersion of liquid-phase droplets for the production of two-dimensional catalytic and three-dimensional nanostructured materials is characterized by high stability of technological processes and the possibility of their controlled operation, environmental safety. The proposed reactor for magnetron electrodispersion can be used for the synthesis and production of not only mono- and bimetallic thin-film materials for biomedical use, but also composite, semiconductor, oxide, nitride, etc. highly dispersed catalytic and nanostructured materials.

\section{E. The potential and role of nanotechnology in the fight against COVID-19}

The modern scientific community is trying to find ways to meet and solve the problems facing humanity. Mankind is facing a pandemic today. In order to overcome it, it is necessary to study in detail this biggest problem.We can talk about our technology and materials as their successful use to obtain materials that are very important today, i.e. to develop antiviral drugs that can be effectively used in the fight against COVID-19. We cannot disagree with Jeremy Ferrar: "The only way out of this pandemic is through science." Humanity today is faced with the greatest danger that can only be overcome with the help of scientific advances. This is a quite difficult task, especially when we look at the properties and construction of the Covid-19 virus(Fig.9). The viral surface proteins spike, envelope and membrane are embedded in a lipid bilayer envelope derived from the host cell. The single-stranded positive-sense viral RNA is associated with the nucleocapsid protein [34].
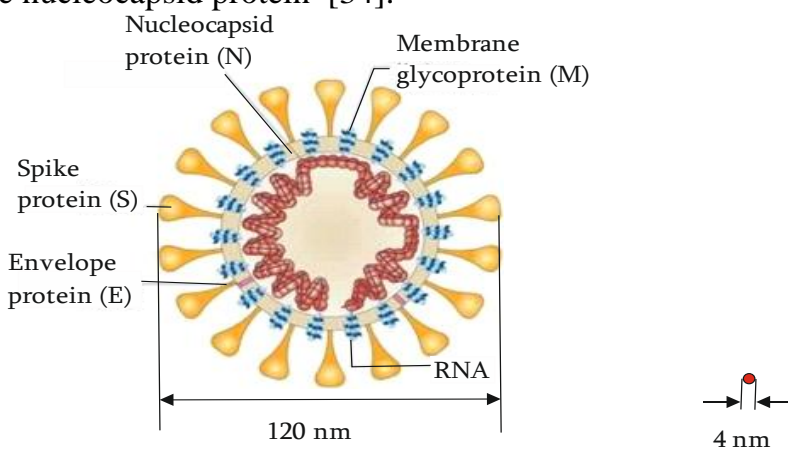

$\mathrm{b}$

Fig.9 Sizes of Covid 19 and our nanoparticle a-Schematic diagram of the SARS coronavirus structure, b- nanostructured material of spherical shape and amorphous structure

To neutralize the virus, materials are needed that can penetrate it. It is expected that the proposed method and technology for the synthesis of spherical nanoparticles, amorphous structure and less than $4 \mathrm{~nm}$ in size can attach to Spike protein $(\mathrm{S})$, or easily penetrate into the Nucleocapsid protein $(\mathrm{N})$, disrupting the structure of the coronavirus and destroying them.

In medicine, a lot of research is being carried out on the use of nanomaterials as antiviral remedies. For example, $\mathrm{ZnO}$ nanoparticles are well known in biomedicine, which are highly effective and do not have toxic side effects $[36,37,38]$.

Our article [39,40] and report [41] at an international conference was devoted to the possibility of obtaining these materials using the innovative method we presented.

In addition, nanostructured materials could become alternative to toxic chemicals used in healthcare facilities as disinfectants. It is believed that nanomaterial coatings and alloys have antiviral and antibacterial properties due to the release of ions that disrupt the functioning of living cells.

\section{CONCLUSIONS}

This paper reveals the advantages of an innovative method and technology for the synthesis of two-dimensional catalytic and three-dimensional nanostructured materials, characterized by high stability of technological processes, the ability to control them, and environmental safety. The proposed reactor for magnetron electrodispersion in vacuum can be used to obtain not only composite, oxide, nitride, etc. highly dispersed catalytic and nanostructured materials, but also nanomaterials for biomedical purposes. 


\section{REFERENCES}

[1] F. Zhu, J. Kim, Kai-Chieh Tsao, J. Zhang, H. Yang, Recent development in the preparation of nanoparticles as fuel cell catalysts, Current Opinion in Chemical Engineering, Vol. 8, 2015, pp.89-97

[2] P. Brault, Erik C.Neyts, Molecular dynamics simulations of supported metal nanocatalyst formation by plasma sputtering, Catalysis Today, Vol. 256, Part 1, 2015, pp 3-12

[3] A. K.Tareen, G. S. Priyanga, S. Behara, T.Thomas, M. Yang, Mixed ternary transition metal nitrides: A comprehensive review of synthesis, electronic structure, and properties of engineering relevance, Progress in Solid State Chemistry, Vol. 53, 2019, pp.1-26

[4] O.K.Alexeeva, V.N.Fateev, Application of the magnetron sputtering for nanostructured electrocatalysts synthesis, International Journal of Hydrogen Energy, Vol. 41, Issue 5, 2016, pp.3373-3386

[5] Sam Zhang, Deen Sun, Yongqing Fu, Hejun Du, Recent advances of superhard nanocomposite coatings: a review, Surface and Coatings Technology, Vol. 167, Issues 2-3, 2003, pp.113-119

[6] D. Medina-Cruz, B. Saleh, A. Vernet-Cru at.st. in Book, Racing for the Surface, Bimetallic Nanoparticles for Biomedical Applications: A Review, 2020 pp. 397-434

[7] Ashish Das, Mukul Shukla, Multifunctional hopeite nanocoating on Ti64 substrates by pulsed laser deposition and radio frequency magnetron sputtering for orthopedic implant applications: A comparative study, Journal of Central South University, vol. 27, 2020, pp. 2198-2209

[8] F. M. El-Hossary, A. M. Abd El-Rahman, M. Raaif, M. Abo El-Kassem, Physical, electrochemical, and biocompatibility characteristics of Ti-Al-N thin film synthesized by DC pulsed magnetron sputtering, Journal of the Australian Ceramic Society, vol. 56, 2020, pp.1155-1165,

[9] H.D.Mejía, Aida M.Echavarría, Gilberto Bejarano G. Influence of Ag-Cu nanoparticles on the microstructural and bactericidal properties of TiAlN $(\mathrm{Ag}, \mathrm{Cu})$ coatings for medical applications deposited by Direct Current (DC) magnetron sputtering, Thin Solid Films,Vol. 687, 2019, pp.137-160,

[10] J.A.Lenis, P.Rico, J.L. Gómez Ribelles, M.A.Pacha Olivenza, M.L.González-Martín, F.J.Bolívar, Structure, morphology, adhesion and in vitro biological evaluation of antibacterial multi-layer $\mathrm{HA}-\mathrm{Ag} / \mathrm{SiO}_{2} / \mathrm{TiN} / \mathrm{Ti}$ coatings obtained by RF magnetron sputtering for biomedical applications, Materials Science and Engineering: C, Vol. 116, 2020, pp.

[11] Kateryna Loza, Marc Heggen, Matthias Epple, Synthesis, Structure, Properties, and Applications of Bimetallic Nanoparticles of Noble Metals, Advanced Science News, Vol. 30, 05 March 2020,1909260, pp. 1-14,

[12] K.Sarakinos, J.Alami, S.Konstantinidis, High power pulsed magnetron sputtering: A review on scientific and engineering state of the art, Surface and Coatings Technology, Vol. 204, Issue 11, 2010, pp.1661-1684,

[13] C. J. Wilson, R. E. Clegg, D. I. Leavesley, M. J. Pearcy, Mediation of Biomaterial-Cell Interactions by Adsorbed Proteins: A Review, Tissue Engineering Vol. 11, No. 1-2, 2005, pp,

[14] Francisco Manzano-Agugliaro and Aránzazu Fernández-García, Surfaces and Interfaces for Renewable Energy, Coatings, Volume 9, Issue 12, 2019, 12, December 2019, pp.838,

[15] Sang-Won Lee, Soohyun Bae, Kyungjin Cho, Seongtak Kim, Jae-Keun Hwang, Wonkyu Lee, Solhee Lee, Ji Yeon Hyun, Seunghun Lee, Sung Bin Choi, Hongpil Chun, Won Mok Kim, Yoonmook Kang*, Hae-Seok Lee*, and Donghwan Kim*, Sputtering of $\mathrm{TiO}_{2}$ for High-Efficiency Perovskite and $23.1 \%$ Perovskite/Silicon 4-Terminal Tandem Solar Cells, ACS Appl. Energy Mater. Voi.2, Issue 9, 2019, pp. 6263-6268,

[16] Corbani, J. F. 1975. "Cathode Sputtering Apparatus.” Patent USA 3 878 085, Priority 5/07/1973, Date of publication 15/04/1975,

[17] Chapin, J. S. 1979. "Sputtering Process and Apparatus." Patent USA 4 166 018, application 31/01/1974, Date of publication 28/08/1979,

[18] Berishvili Z.V., Gadakhabadze i.i., Kordzaxia i.i., Dekanozishvili G.G. Planar Magnetron Sputtering Device: a New Generation of Magnetron Sputtering Design and Technology, USA, Journal of Physical Science and Application, V., 7, N, 5, 2017, pp. 28-39.

[19] Berishvili, Z., Skhiladze, G., and Shioshvili, S. 1983. The Arrangement of Ion-Plasma Sputtering in Vacuum. Author's Certificate, № 1160761 (USSR), 1983, Date of publication 8.02.1985.

[20] Berishvili, Z., Gadakhabadze, I., Skhiladze, G., and Shioshvili, S. 1984. The Arrangement of Ion-Plasma Sputtering of Materials in Vacuum. Author’s Certificate, № 1244960 (USSR), 1984, Date of publication 15.03.1986.
[21] BERISHVILI, ZAUR, Planar Magnetron Sputtering Device. GE P 2016 6512 B, 2015.05.28, Date of publication 2016.03.25, № 6. Appl. for international patent, WIPO|PCT , WO 2016/189337 A1, Date of publication № WO 2016/189337 01.12.2016. Appl. of India patent, № 201717040689, November 14, 2017.

[22] Berishvili Z.V., Gadakhabadze i.i., Kordzaxia i.i., Dekanozishvili G.G. Planar Magnetron Sputtering Device: a New Generation of Magnetron Sputtering Design and Technology, USA, Journal of Physical Science and Application, V., 7, N, 5, 2017, pp. 28-39.

[23] V. M. Kozhevin, D. A. Yavsin, V. M. Kouznetsov, V. M. Busov, V. M Mikushkin, S. Yu. Nikonov, and S. A. Gurevich, Granulated metal nanostructure deposited by laser ablation accompanied by cascade drop fission, Journal of Vacuum Science \& Technology B, Vol. 18, Issue 3 , 2000 , pp.1402.

[24] Ekaterina S. Lokteva, Anton A. Peristyy, Natalia E. Kavalerskaya, Elena V. Golubina, Lada V. Yashina, Tatiana N. Rostovshchikova, Sergey A. Gurevich, Vladimir M. Kozhevin, Denis A. Yavsin, and Valery V. Lunin, Laser electrodispersion as a new chlorine-free method for the production of highly effective metal-containing supported catalysts, Pure and Applied Chemistry, Volume 84, Issue 3, 18 Jan 2012, pp. 495-508.

[25] Elena V. Golubina, Tatiana N. Rostovshchikova, Ekaterina S. Lokteva, Konstantin I. Maslakov, Sergey A. Nikolaev, Tolganay B. Egorova, Sergey A. Gurevich, Vladimir M. Kozhevin, Denis A. Yavsin and Anatoly Ye. Yermakov. Chlorobenzene hydrodechlorination on bimetallic catalysts prepared by laser electrodispersion of NiPd alloy, Pure and Applied Chemistry, Volume 90, Issue 11, 18 Aug 2018, pp.

[26] T.N.Rostovshchikova, V.V.Smirnov, V.M.Kozhevin, D.A.Yavsin, M.A.Zabelin, I.N.Yassievich, S.A.Gurevich, New size effect in the catalysis by interacting copper nanoparticles, Applied Catalysis A: General. Vol. 296, Issue 1, 2005, pp. 70-79.

[27] Кожевин В. М., Горохов М. В., Гуревич С. А., Явсин Д., А., Кузьмин И., А., способ получения наночастиц и устройство для его осуществления, патент RU 2412108, 19,01, 2009 , опубликовано 20.02.2011,

[28] Д.А.Карпов, В.Н. Литуновский, Способ получения осажденных на носителе наночастиц металла или полупроводника, патент RU 2265076, 20.12.2004, JP 2008-013810 A, 24.01.2008, опубликовано 27.01.2010,

[29] BERISHVILI, ZAUR, "Method for Production of Nanomaterial in Vacuum and Magnetron Sputtering Device for its Embodiment", (2018), Georgian Patent № AP 2018 14793, C 23C 14/35, Publication Date: 2019.05.27, № 6(518). WO/2019/224564, International Application PCT/GE2019/050002-14793, 17 May 2019, Publication Date: 28.11.2019, Appl. of India patent, № 202017046523, October 26, 2020.

[30] J. T. Gudmundsson, Physics and technology of magnetron sputtering discharges, Plasma Sources Science and Technology, Vol. 29, Number 11,12 November 2020,

[31] André Anders, Yuchen Yang, Direct observation of spoke evolution in magnetron sputtering, Applied Physics Letters, Vol. 111, Issue 6, August 2017,

[32] Matjaž Panjan, Simon Loquai, Jolanta Ewa Klemberg-Sapieha and Ludvik Martinu, Non-uniform plasma distribution in dc magnetron sputtering: origin, shape and structuring of spokes, Plasma Sources Science and Technology, Volume 24, Number 6, 27 October 2015,

[33] Kozhevin V.M. et al., (), "Granulated metal nanostructure deposited by laser ablation accompanied by cascade drop fission" J. Vac. Sci. Technol. B 18, 2000, pp.140,

[34] Husain Dhobi, Suvesksha Karki, Bikrant Karki, Bikram Shrestha, Anil Karki, Rosha Basnet, Killing Coronavirus Before They Enter Human Body Saddam, International Journal of Multidisciplinary Sciences and Advanced Technology, 2020, pp.90-96,

[35] Ü. Özgür, Ya. I. Alivov, C. Liu, A. Teke, M. A. Reshchikov, $\underline{S}$.

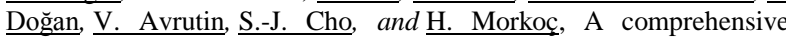
review of $\mathrm{ZnO}$ materials and devices, Journal o Applied Physics, Vol. 98, Issue 4.

[36] Qi, K., Cheng, B., Yu, J., \& Ho, W. (2017). Review on the improvement of the photocatalytic and antibacterial activities of $\mathrm{ZnO}$. Journal of Alloys and Compounds,2017, pp.792-820,

[37] Kipiani M.J., "Planar Reactive Magnetron Sputtering to Obtain Dielectrics and Transparent Conductive Thin Films", International Journal of New Technology and Research (IJNTR) vol. 6, Issue-6, Published online, June 2020, pp. 45-50,

[38] Zaur Berishvili, Marina Kipiani, Irakli Kordzakhia ,Guram Dekanozishvili, "An innovative method for the synthesis of monodisperse $\mathrm{ZnO}$ nanoparticles for biomedical applications", 
Innovative Magnetron Sputtering For the Synthesis of Catalytic and Nanostructured Materials and Its Possible Using In Biomedicine and In the Fight against COVID-19

International Journal of New Technology and Research (IJNTR) vol. 6, Issue-8, Published online, August 2020, pp. 16-20,

[39] Zaur Berishvili, Marina Kipiani, Irakli Kordzakhia ,Guram Dekanozishvili, innovative Magnetron Sputtering Device for the Synthesis of Highly Efficient Catalytic Materials, $3^{\text {rd }}$ Edition of Catalysis Virtual 2020, October 28-29 2020, pp.24. 